\title{
GLOBAL CURVE OF POSITIVE SOLUTIONS FOR $\varphi$ - LAPLACIAN DIRICHLET BVP WITH AT MOST ONE TURNING POINT
}

\author{
Abdelhamid Benmezaï, Salima Mechrouk and Sotiris K. Ntouyas
}

Abstract. Under suitable conditions we prove that the set of positive solutions to the $\varphi$-Laplacian boundary value problem

$$
-\left(\varphi\left(u^{\prime}\right)\right)^{\prime}=\lambda f(u) \text { in }(0,1) ; u(0)=u(1)=0,
$$

where $\lambda>0$ is a real parameter, $\varphi$ is an odd increasing homeomorphism of $\mathbb{R}$ and $f \in$ $C([0,+\infty),[0,+\infty))$, consists on a curve $\|u\| \rightarrow \lambda(\|u\|)$.

Mathematics subject classification (2010): 34B15, 34B16.

Keywords and phrases: second order bvp, positive solution, global curve.

\section{REFERENCES}

[1] I. Addou, F. Ammar Khodja, Sur le nombre de solutions d'un probleme aux limites non lineaire, C. R. Acad. Sci. Paris, 321, Serie 1 (1995), pp. 409-412.

[2] I. ADDOU AND A. BENMEZAI, Exact number of positive solutions for a class of quasilinear boundary value problems, Dynam Systems Appl., 8 (1999), 147-180.

[3] I. AdDou AND A. BEnmeZAi, Boundary-value problems for the one-dimensional p-Laplacian with even superlinearity, Electron. J. Diff. Eqns., Vol. 1999, No. 9,(1999), 1-29.

[4] I. Addou, A. Benmezai, S. M. Bouguima And M. Derhab, Exactness results for generalized Ambrosetti-Brezis-Cerami problem and related one-dimensional elliptic equations, Electron. J. Diff. Eqns., Vol. 2000, No. 66 (2000), pp. 1-34.

[5] A. Ambrosetti, On the exact number of positive solution of convex nonlinear problem, Boll. Unione Mat. Ital. A, 15 (1978), 610-615.

[6] A. Ambrosetti And P. Hess, Positive solutions of asymptotically linear elliptic eigenvalue problems, J. Math. Anal. Appl., 73 (1980), 411-422.

[7] A. BenMeZAI, Complete description of the solution set to a strongly nonlinear O.D.E., E. J. Qualitative Theory of Diff. Equ., 9 (2003), 1-18.

[8] A. BenmezaI, Positive solutions for a second order two point boundary value problem, Communication in Applied Analysis, 14, 2 (2010), 177-190.

[9] A. Benmezai, S. Djebali, T. Moussaoui, Positive solution for $\phi$-Laplacian Dirichlet bvps, Fixed Point Theory, 8 (2007), 167-186.

[10] A. Benmezai, S. DJebali, T. Mouss aoui, Multiple positive solution for $\phi-$ Laplacian Dirichlet bvps, PanAmer. Math. J., 17 (2007), 53-73.

[11] A. CASTRO, S. GADAM, R. ShIVAJI, Evolution of positive solution curve in semi-positone problems with concave nonlinearities, J. Math. Anal. Appl., 245 (2000), 282-293.

[12] C. DE-Coster, Pairs of positive solutions for the one-dimensional p-Laplacian, Nonlinear Anal., 23 (1994), 669-681.

[13] D. De-Figueiredo, Positive solutions of semilinear elliptic problems, Lecture Notes in Math., 957 (1982), 34-87.

[14] H. Dang, K. Schmitt, R. Shivaji, On the number of solutions of bvp involving $p$-Laplacian, Electron. J. Diff. Eqns., Vol. 1996, 1 (1996), 1-9.

[15] P. De Mottoni, A. Tesei, On a class of non linear eigenvalue problems, Boll. Unione Mat. Ital. B, 14 (1977), 172-189. 
[16] T. Ding AND F. ZANOLIn, Time maps for the solvability of periodically perturbed nonlinear Duffing equations, Nonlinear Anal., 17, 7 (1991), 635-653.

[17] García-Huidobro M., R. ManÁSEvich, J.R. Ward,Positive solutions for equations and systems with p-Laplace-like operators, Advances in Diffrential Equations, Vol. 14, 5-6 (2009), 401-432.

[18] M. García-Huidobro, R.F. ManÁSEVICH, F. ZANolin, A Fredholm-like result for strongly nonlinear second order O.D.E.'s, J. Differential Equations, 114 (1994), 132-167.

[19] M. García-Huidobro, R.F. ManÁsevich, F. Zanolin, On a pseudo Fučík spectrum for strongly nonlinear second order O.D.E.'s and an existence result, J. Comput. Appl. Math., 52 (1994), 219-239.

[20] M. García-Huidobro, R.F. Manásevich, F. Zanolin, Strongly nonlinear second order O.D.E.'s with rapidly growing terms, J. Math. Anal. Appl., 202 (1996), 1-26.

[21] M. García-Huidobro, P. UBilla, Multiplicity of solutions for a class of nonlinear second-order equations, Nonlinear Anal., 28 (1997), 1509-1520.

[22] Y.X. HUANG, Existence of positive solutions for a class of the p-Laplace equations, J. Austral. Math. Soc. Ser. B, 36 (1994), 249-264.

[23] P.F. Hsien, Y. SibuYa, Basic theory of ordinary differential equations, Springer-Verlag, 1999.

[24] H.G. KAPER, M. KNAPP, M.K. KwONG, Existence theorems for second order bvps, Diff. Int. Eqns., 4 (1991), 543-554.

[25] H.B. Keller, D.S. Cohen, Some positone problems suggested by nonlinear heat generation, J. Math. Mech., 16 (1967), 1361-1376.

[26] P. Korman, Y. Li, Generalized averages for solutions of two point Dirichlet problem, J. Math. Anal. Appl., 239 (1999), 478-484.

[27] P. Korman, T. OUYANG, Exact multiplicity results for a class of boundary-value problems with cubic nonlinearities, J. Math. Anal. Appl., 194 (1995), 328-341.

[28] P. Korman, Y. LI, On the exactness of an S-shaped bifurcation curve, Proc. Amer. Math. Soc., 127 (1999), 1011-1020.

[29] T. LAETSCH, The number of solutions of a nonlinear two point bvp, Indiana Univ. Math. J., 20 (1970) $1-13$.

[30] R. Manásevich, F. I. NJoku and F. Zanolin, Positive solutions for the one-dimensional p-Laplacian, Diff. Int. Eqns., 8 (1995), 213-222.

[31] R. MANÁSEVICH AND F. ZANOLIn, Time mappings and multiplicity of solutions for the onedimensional p-Laplacian, Nonlinear Anal., 21, 4 (1993), 269-291.

[32] F. I. NJOKu, F. ZANOLIn, Positive solutions for the two point BVP's: Existence and multiplicity results, Nonlinear Anal., 13 (1989), 1329-1338.

[33] Z. OpIAL, Sur les solutions périodiques de l'équation différentielle $x^{\prime \prime}+g(x)=p(t)$, Bulletin de l'académie Polonaise des sciences, Série des sci. math., astr. et phys. Vol. VIII, No. 3, 1960.

[34] B. P. RYNNE, A global curve of stable positive solutions for a p-Laplacian problem, Electron. J. Diff. Eqns., Vol. 2010, 58 (2010), 1-12.

[35] P. UBiLla, Multiplicity results for the 1 -dimensional generalized p-Laplacian, J. Math. Anal. Appl., 190 (1995), 611-623. 